\title{
ROLA CARYCY MARII-IRENY LEKAPENY W RECEPCJI ELEMENTÓW BIZANTYŃSKIEGO MODELU WŁADZY W PIERWSZYM PAŃSTWIE BULGARSKIM**
}

Urodzona ok. 912 r. Maria Lekapena była wnuczką cesarza bizantyńskiego Romana I, formalnie dzielącego tron ze swym zięciem, Konstantynem VII Porfirogenetą w latach 919-944. Najprawdopodobniej przyszła ona na świat w stolicy Bizancjum jako najstarsze dziecko Krzysztofa Lekapena, podniesionego przez ojca do rangi współcesarza w 921 r. oraz jego żony Zofii, córki Niketasa Słowianina. W 927 r. Maria poślubiła władcę Bułgarii, Piotra. Jej małżeństwo, uroczyście zawarte w Konstantynopolu, miało za zadanie umocnić świeżo podpisany pokój bizantyńsko-bułgarski ${ }^{1}$. Zdaniem Liutpranda z Cremony (ok. 920-972), by podkreślić znaczenie tego mariażu dla relacji między obu państwami, Maria wychodząc za mąż przybrała nowe imię - Irena (Pokój)². Bułgarską władczynią pozostała aż do swej śmierci na początku lat 60 . X w.,

* Dr Zofia A. Brzozowska - asystent naukowy w Centrum Badań nad Historią i Kulturą Basenu Morza Śródziemnego i Europy Południowo-Wschodniej im. prof. Waldemara Cerana (Ceraneum) na Uniwersytecie Łódzkim oraz pracownik Katedry Filologii Słowiańskiej na Wydziale Filologicznym Uniwersytetu Łódzkiego; e-mail: zbrzozowska@uni.lodz.pl.

${ }^{* *}$ Niniejszy artykuł powstał $\mathrm{w}$ ramach projektu sfinansowanego ze środków Narodowego Centrum Nauki, przyznanych na podstawie decyzji nr DEC-2014/14/M/HS3/00758 (Państwo butgarskie w latach 927-969. Epoka cara Piotra I Pobożnego).

${ }^{1} \mathrm{Na}$ temat pochodzenia i biografii Marii Lekapeny zob. S. Runciman, The Emperor Romanus Lecapenus and His Reign. A Study of Tenth-Century Byzantium, Cambridge 1969, 78 i $97-$ 98; S. Georgieva, The Byzantine Princesses in Bulgaria, „Byzantinobulgarica” 9 (1995) 166170; J. Shepard, A marriage too far? Maria Lekapena and Peter of Bulgaria, w: The Empress Theophano. Byzantium and the West at the turn of the first millennium, ed. A. Davids, Cambridge 1995, 136-139; В. Гюзелев, Значението на брака на цар Петър (927-969) с ромейката Мария-Ирина Лакапина (911-962), w: Културните текстове на миналото - носители, символи, идеи, t. 1: Текстовете на историята, история на текстовете. Материали от Юбилейната международна конферениия в чест на 60-годишнината на проф. д.и.н. Казимир Попконстантинов, Велико Търново, 29-31 октомври 2003 г., София 2005, 27-33; В. Игнатов, Българските иарици. Владетелките на България от VII до XIV в., София 2008, 13-14; С. Георгиева, Жената в българското средновековие, Пловдив 2011, 312-316.

${ }^{2}$ Por. Liudprandus Cremonensis, Antapodosis III 38, ed. P. Chiesa, CCCM 156, Turnholti 1998, 86. Na temat ideologicznego znaczenia pokoju bizantyńsko-bułgarskiego z roku 927 zob. K. Marinow, In the Shackles of the Evil One. The Portrayal of Tsar Symeon I the Great (893-927) in the Oration On the treaty with the Bulgarians, „Studia Ceranea” 1 (2011) 157-190; tenże, Peace in 
zdaniem niektórych uczonych przez cały ten czas z powodzeniem wywiązując się z powierzonej jej roli gwarantki pokoju. Stosunki między cesarstwem a Bułgarią miały się bowiem ponownie zaostrzyć właśnie w szóstej dekadzie X stulecia, a zatem wtedy, gdy na scenie politycznej zabrakło już Lekapeny ${ }^{3}$.

W starszej historiografii bułgarskiej spotkać można było o wiele dalej idące przypuszczenia na temat roli, odgrywanej przez Marię w Presławiu. Wasił Złatarski (14 XI 1866 - 15 XII 1935) i Petyr Mutafczijew (4 VII 1883 - 2 V 1943), a w ślad za nimi późniejsi historycy, przypisywali carycy znaczny wpływ na polityczne posunięcia jej męża. Władczyni miała ponadto zaszczepić na gruncie bułgarskim wiele elementów wschodniorzymskiej teorii władzy, przeprowadzić swego rodzaju „bizantynizację” starobułgarskiej kultury politycznej, a nawet pełnić nieomal rolę szpiega Konstantynopola na presławskim dworze ${ }^{4}$.

W tym miejscu należy podkreślić, że poglądy wspomnianych badaczy nie znajdują potwierdzenia $\mathrm{w}$ zachowanym materiale źródłowym. Warto mieć na uwadze fakt, iż autorzy bizantyńscy, zamieściwszy w swych przekazach wiele szczegółowych informacji na temat okoliczności ślubu Marii i Piotra, zawar-

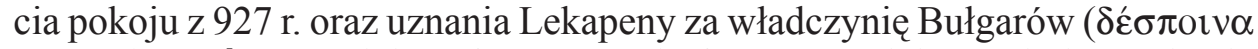

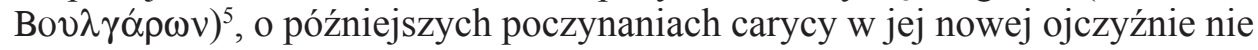
piszą właściwie nic. Na kartach Kontynuacji Teofanesa odnaleźć możemy

the House of Jacob. A Few Remarks on the Ideology of Two Biblical Themes in the Oration On the Treaty with the Bulgarians, „Bulgaria Mediaevalis” 3 (2012) 85-93.

${ }^{3}$ Por. M.J. Leszka, Wizerunek władców pierwszego państwa bułgarskiego w bizantyńskich źródłach pisanych (VIII - pierwsza połowa XII w.), Byzantina Lodziensia 7, Łódź 2003, 128; tenże, Образът на българския ияар Борис II във византийските извори, „Studia Balcanica” 25 (2006) 146-147; tenże - K. Marinow, Carstwo bułgarskie. Polityka - społeczeństwo - gospodarka - kultura. 866-971, Warszawa 2015, 160 i 174.

${ }^{4}$ Por. В.И. Златарски, История на българската държава през средните векове, t. I/2, Първо българско Царство. От славянизацията на държавата до падането на Първото иарство (852-1018), София 1927, 535-536; П. Мутафчиев, История на българския народ (6811323), София 1986, 201; Игнатов, Българските иарици, s. 14.

${ }^{5}$ Por. Theophanes Continuatus VI 22-23, ed. I. Bekker, CSHB [48], Bonnae 1838, 412-415; Symeon Magister et Logotheta, Chronicon 136, 45-51, ed. S. Wahlgren, CFHB (Series Berolinensis) 44/1, Berolini - Novi Eboraci 2006, 326-329; Joannes Scylitzes, Synopsis historiarum X 18, ed. I. Thurn, CFHB (Series Berolinensis) 5, Berolini 1973, 222-224; Joannes Zonaras, Epitomae historiarum XVI 18-19, ed. Th. Büttner-Wobst, CSHB [31], Bonnae 1897, 473-475; Leo Grammaticus, Chronographia 115, ed. I. Bekker, CSHB [34], Bonnae 1842, 315-317; Georgius Monachus, Vitae imperatorum recentiorum IX 28-34, ed. I. Bekker, CSHB [48], Bonnae 1838, 904-907. O małżeństwie Marii Lekapeny z Piotrem wspomina też Konstantyn VII Porfirogeneta na kartach O zarzadzaniu państwem, wartościując ten fakt jednoznacznie negatywnie (Constantinus Porphyrogenitus, De administrando imperio 13, ed. G. Moravcsik, CFHB 1, Washington 1967, 72-74). Analizę przekazu tego ostatniego źródła znajdzie czytelnik w artykule: Т. Тодоров, Константин Багренородни и династичният брак между владетелските домове на Преслав и Константинопол от 927 2., „Преславска книжовна школа” 7 (2003) 391-398. Na temat tytułu nadanego Marii przy okazji ślubu z bułgarskim władcą zob. М. Христодулова, Титул и регалии болгарской владетельниць в эпоху средневековья (VII-XIV в6.), „Études Balkaniques” 3 (1978) 142-143; Shepard, A marriage 
jedynie wzmiankę o tym, iż Maria kilkakrotnie podróżowała do Konstantynopola, aby odwiedzić swoich bliskich ${ }^{6}$. Co więcej, o politycznej aktywności małżonki Piotra nie wspominają też ani rodzime źródła bułgarskie, ani obce (np. interesujący się jej osobą Liutprand z Cremony) ${ }^{7}$.

Teza o wyjątkowo wysokiej pozycji carycy Marii na presławskim dworze oraz posiadaniu przez nią realnej władzy politycznej, a tym samym możliwości wpływania na decyzje Piotra, wobec milczenia źródeł pisanych, może znajdować potwierdzenie jedynie w materiale sfragistycznym. Nie ulega najmniejszej wattpliwości fakt, iż w latach 927-945 bułgarski władca zawsze wyobrażany był na swych oficjalnych pieczęciach w towarzystwie małżonki. Do naszych dni dotrwało relatywnie sporo tego rodzaju artefaktów. Praktyka ta, z przyczyn o których będzie jeszcze mowa w dalszej partii niniejszego szkicu, została zarzucona w późniejszym okresie rządów Piotra - w latach 945-969 występuje on już na pieczęciach sam $^{8}$.

Specjalista w zakresie średniowiecznej sfragistyki bułgarskiej i bizantyńskiej, Ivan Jordanov, wydziela w swym studium trzy typy pieczęci Piotra i Marii z lat 927-945:

I. Piotr i Maria - bazyleusowie/cesarze Bułgarów (po 927 r.) - na rewersie znajduje się wizerunek Piotra i Marii, ukazanych jako para nieomal równorzędnych władców. Cara wyobrażono po lewej stronie kompozycji, carycę zaś po prawej ${ }^{9}$. Oboje przedstawieni zostali w oficjalnym stroju konstantynopolitańskich bazyleusów: ich głowy wieńczą

too far, s. 128-129; А. Николов, Политическа мисъл в ранносредновековна България (средата на IX-края на X в.), София 2006, 134.

${ }^{6}$ Por. Theophanes Continuatus VI 35, CSHB [48], s. 422. Zob. Runciman, The Emperor, s. 102.

${ }^{7}$ Osoba Marii Lekapeny oraz okoliczności zawarcia przez nią małżeństwa z bułgarskim władcą przykuwały uwagę przebywającego w Konstantynopolu w 968 r. Liutpranda z Cremony z oczywistych względów - celem jego wizyty nad Bosforem było wynegocjowanie zgody cesarza Nikefora II Fokasa (963-969) na ślub ,urodzonej w purpurze” Bizantynki z synem Ottona I (król Niemiec: 936973, cesarz: 962-973). Mariaż bizantyńsko-bułgarski z 927 r. mógł być w tych rokowaniach ważnym argumentem, świadczącym o tym, iż zasada, wedle której kobieta z cesarskiego rodu nie mogła poślubić cudzoziemskiego władcy, nie była na konstantynopolitańskim dworze ściśle przestrzegana. Zob. T. Wolińska, Konstantynopolitańska misja Liutpranda z Kremony (968), w: Cesarstwo bizantyńskie. Dzieje. Religia. Kultura. Studia ofiarowane Profesorowi Waldemarowi Ceranowi przez uczniów na 70-lecie Jego urodzin, red. P. Krupczyński - M.J. Leszka, Łask - Łódź 2006, 208-212.

${ }^{8}$ Por. Georgieva, The Byzantine Princesses, s. 167; Shepard, A marriage too far, s. 141-148; И. Йорданов, Корпус на печатите на Средновековна България, София 2001, 58-66 і 163-165; Гюзелев, Значението на брака, s. 27; Георгиева, Жената, s. 313-315; Leszka - Marinow, Carstwo butgarskie, s. 158-160.

${ }^{9}$ Analizując wyobrażenia na pieczęciach i monetach stosuję w niniejszym artykule porządek rozpowszechniony $\mathrm{w}$ publikacjach anglojęzycznych, $\mathrm{tj}$. opisuję przedstawienie od strony obserwatora. Z punktu widzenia osób ukazanych na pieczęci lub monecie określenie kierunków będzie odwrotne: car Piotr, dla obserwatora znajdujący się z lewej strony kompozycji, de facto umiejscowiony został po prawej - ten sposób opisu preferuje m.in. w swych wydanych w języku bułgarskim pracach Ivan Jordanov. 
stemmy, Maria ma na sobie loros. Bułgarscy władcy trzymają między sobą krzyż, uchwyciwszy go na tej samej wysokości. Inskrypcja wspo-

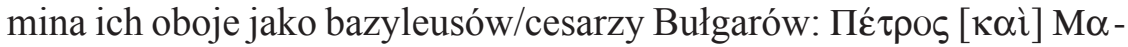

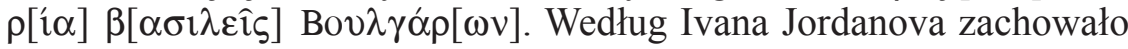
się dziewięć tego typu artefaktów ${ }^{10}$.

II. Piotr i Maria - autokratorzy Bułgarów/auguści i bazyleusowie (lata 40. X w.) - istnieje tylko siedem egzemplarzy tego typu pieczęci. Zdobiący je wizerunek pary carskiej zasadniczo nie różni się od opisanego wyżej. Ze względu na zły stan zachowania wszystkich zaliczanych do omawianego typu zabytków, towarzyszący przedstawie-

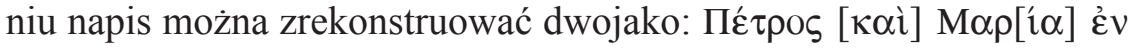

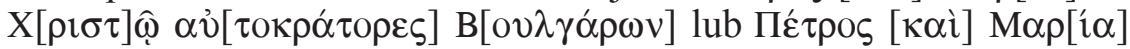
$\dot{\varepsilon} v X[\rho i \sigma \tau] \hat{\omega} \alpha \hat{v}[\gamma O v \sigma \tau O \imath] \beta[\alpha \sigma \imath \lambda \varepsilon \hat{\imath} \varsigma]^{11}$.

III. Piotr i Maria, pobożni bazyleusowie/cesarze (lata 40. - 50. X w.) - najbardziej rozpowszechniony typ. Zdaniem Ivana Jordanova zachowało się 31 tego rodzaju artefaktów. Nowsze opracowania wymieniają ich ponad 60. Na rewersie pieczęci odnajdujemy wizerunek Piotra i Marii, wykazujący znaczne podobieństwo do analizowanego wyżej przedstawienia. Para trzyma krzyż - car z lewej, a caryca z prawej strony. W przeciwieństwie do wyobrażeń napieczętnych typu I i II, dłonie monarchów zostały umiejscowione na niejednakowej wysokości. W większości przypadków ręka władcy znajduje się wyżej, istnieją jednak również egzemplarze, na których to Maria ujmuje krzyż ponad dłonią swego męża. Inskrypcja wspomina już tylko Piotra, nazywając

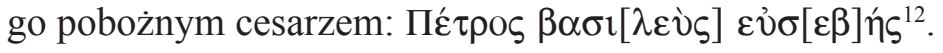

Trudno dać jednoznaczną odpowiedź na pytanie, czy podobny - niewątpliwie przejęty $\mathrm{z}$ bizantyńskiego systemu autoprezentacji władcy - kanon przedstawiania bułgarskiej pary monarszej stosowany był również na monetach. Niestety, do naszych dni nie zachował się ani jeden artefakt, który można jednoznacznie zidentyfikować jako przykład pieniądza kruszcowego, wybitego w Bułgarii za panowania cara Piotra. Asen Czilingirow proponuje uznawać za monety wspomnianego władcy tajemnicze srebrniki, z których kilka przechowywanych jest aktualnie w zbiorach muzealnych Ermitażu. Znajduje się na nich cyrylicki napis z imieniem Piotra ${ }^{13}$.

${ }^{10}$ Por. Йорданов, Корпус на печатите, s. 58-59; Гюзелев, Значението на брака, s. 27; И. Божилов - В. Гюзелев, История на средновековна България. VII-XIV в., София 2006, 275.

${ }^{11}$ Por. Shepard, A marriage too far, s. 141-143; Йорданов, Корпус на печатите, s. 59-60; Гюзелев, Значението на брака, s. 27; Георгиева, Жената, s. 313-315; Leszka - Marinow, Carstwo butgarskie, s. 160.

${ }_{12}$ Por. Shepard, A marriage too far, s. 143-146; Йорданов, Корпус на печатите, s. 60-63; Гюзелев, Значението на брака, s. 27.

13 Por. М.П. Сотникова - И.Г. Спасский, Тысячелетие древнейших монет России. Сводный каталог русских монет Х-ХІ вв., Ленинград 1983, 86-96; А. Чилингиров, Монетите 
Wracając do głównego nurtu naszych rozważań należy natomiast stwierdzić, iż umieszczenie wizerunku Marii-Ireny na pieczęciach jest wydarzeniem bezprecedensowym w dziejach średniowiecznej sfragistyki bułgarskiej - żadna władczyni przed Lekapeną i żadna po niej nie została uwieczniona w ten sposób. Znawcom zagadnienia znane są również tylko nieliczne - i to znacznie późniejsze - przykłady ukazania monarchini bułgarskiej na monetach, wybijanych przez jej małżonka: zaszczytu tego dostąpiła m.in. Teodora II (13491371), żona cara Jana Aleksandra (1331-1371) ${ }^{14}$.

Pieczęcie z wizerunkami Piotra i Marii świadczą też o wpływie bizantyńskiego systemu autoprezentacji władcy na starobułgarską kulturę polityczną. Nie ulega najmniejszej wątpliwości fakt, iż analizowane tu przedmioty zostały wykonane na wzór pieczęci i monet bizantyńskich z X w., na których wyobrażenie dwóch lub trzech osób sprawujących wspólnie rządy (współcesarzy, syna z matką-regentką) pojawiało się dość często. Można zaryzykować przypuszczenie, że bezpośrednim źródłem inspiracji dla osób ustalających program ikonograficzny sigillum Piotra z lat $927-945$ były pieczęcie i monety wykonane w Bizancjum w czasie sprawowania regencji przez cesarzową Zoe Karbonopsinę przy swoim małoletnim synu, Konstantynie VII Porfirogenecie (914-919), lub w okresie współrządów Konstantyna VII z Romanem I Lekapenem (920-944) i jego synem Krzysztofem (921-931) ${ }^{15}$. Niektóre ze wspomnianych artefaktów z pewnością trafiły na terytorium państwa cara Piotra. Świadczą o tym chociażby znaleziska archeologiczne: na obszarze Bułgarii odkryto m.in. pieczęcie z wyobrażeniami Konstantyna VII Porfirogenety, Romana I Lekapena i jego syna Krzysztofa ${ }^{16}$.

на киевските князе и монетите на българския цар Петър I, София 2009, 13-20 і 39-43. Badacze wymieniają łącznie dwanaście tego rodzaju artefaktów.

${ }^{14}$ Por. Georgieva, The Byzantine Princesses, s. 167 і 201; Игнатов, Българските царици, s. 85-87; Георгиева, Жената, s. 348 i 352-354. Najprawdopodobniej w latach 40. XIII w. na monetach ukazywana była sprawująca regencję caryca Irena Komnena wraz ze swoim synem Michałem I Asenem (1246-1256). Istnieje również niewielka grupa miedzianych numizmatów widyńskiego cara Jana Stracimira (1356-1396), na których władca ten przedstawiony został wraz ze swą małżonką Anną, zob. Игнатов, Българските и̧арици, s. 89-90; Георгиева, Жената, s. 322-323 і 348.

${ }^{15}$ Zachowały się pieczęcie i monety bizantyńskie z wizerunkiem Zoe i Konstantyna VII z lat 914-919, a także artefakty z przedstawieniami: Konstantyna VII i Romana I Lekapena (920-944) oraz Konstantyna VII, Romana I i jego syna Krzysztofa (921-931). Por. Ph. Grierson, Byzantine Coins, London - Berkeley - Los Angeles 1982, 179-182 i 367-368; N. Oikonomides, A Collection of Dated Byzantine Lead Seals, Washington 1986, 64-65. Zastanawiające niektórych badaczy zjawisko, tj. umiejscowienie na kilku pieczęciach bułgarskich z lat 40. - 50. X w. ręki Marii ponad dłonią jej męża, można najprawdopodobniej wytłumaczyć tym, iż sporządzający sigillum artysta wzorował się na solidzie bizantyńskim z okresu regencji Zoe Karbonopsiny. Na artefaktach tego rodzaju Konstantyn VII ukazywany był po lewej stronie kompozycji, jego matka zaś - po prawej. Cesarzowa ujmowała jednak krzyż wyżej niż jej syn. Analogiczny schemat pojawia się na interesujących nas tu pieczęciach Piotra i Marii, zob. Grierson, Byzantine Coins, pl. 43, nr 779; Shepard, A marriage too far, s. 143-144.

${ }^{16}$ Por. I. Jordanov, Corpus of Byzantine Seals from Bulgaria, t. 3/1, Sofia 2009, 90-92. 
Materiału sfragistycznego z okresu rządów cara Piotra nie można jednak uznawać za dowód trwałej recepcji na gruncie bułgarskim bizantyńskiej praktyki umieszczania na monetach i pieczęciach wizerunków władczyń (matek lub małżonek bazyleusów). Po roku 945, a zatem najprawdopodobniej jeszcze za swego życia ${ }^{17}$, caryca Maria znika z pieczęci. Analizowane tu zjawisko nie ma również kontynuacji w późniejszych wiekach. Fakt, iż kilka bułgarskich monarchiń z XIII-XIV w. zostało wyobrażonych na monetach, świadczy raczej o ponownym zaadoptowaniu na interesującym nas tu obszarze wzorców bizantyńskich, niż o przetrwaniu pewnej rodzimej tradycji, ukształtowanej za panowania Piotra i Marii.

Ani przekaz źródeł pisanych, ani zachowany materiał sfragistyczny nie pozwala na formułowanie jednoznacznych wniosków na temat rzeczywistego wpływu carycy Marii na decyzje jej męża. Próbując znaleźć odpowiedź na pytanie, czy Lekapena przejawiała jakieś aspiracje polityczne i była osobą aktywną w sferze publicznej?, warto zestawić jej postać z sylwetką innej Bizantynki, której los wyznaczył rolę słowiańskiej władczyni - Anny Porfirogenetki, córki cesarza Romana II (959-963), siostry Bazylego II Bułgarobójcy (976-1025) i Konstantyna VIII (1025-1028), która w 988/989 r. została żoną księcia ruskiego Włodzimierza I Światosławowicza (978-1015) $)^{18}$. Porównanie statusu obu władczyń zawiera poniższa tabela:

\begin{tabular}{|c|c|c|}
\hline & $\begin{array}{c}\text { MARIA } \\
\text { CARYCA BULGARSKA OD } 927 \mathrm{R} .\end{array}$ & $\begin{array}{c}\text { ANNA } \\
\text { KSIĘŻNA RUSKA OD 988/989 R. }\end{array}$ \\
\hline $\begin{array}{c}\text { STATUS } \\
\text { PRZED ŚLUBEM }\end{array}$ & $\begin{array}{l}\text { Pochodzi z rodu Lekapenów, jest } \\
\text { wnuczką cesarza Romana I, formalnie } \\
\text { dzielącego tron z Konstantynem VII, } \\
\text { córką jego syna Krzysztofa (współce- } \\
\text { sarza w latach 921-931). }\end{array}$ & $\begin{array}{l}\text { Jest porfirogenetka, tj. „urodzoną } \\
\text { w purpurze”, córką panującej pary } \\
\text { cesarskiej, Romana II z dynastii ma- } \\
\text { cedońskiej i Teofano, siostrą cesarzy } \\
\text { Bazylego II i Konstantyna VIII. }\end{array}$ \\
\hline
\end{tabular}

${ }^{17} \mathrm{~W}$ literaturze przedmiotu dominuje pogląd, iż Maria zmarła w 963 r., a usunięcie wizerunku carycy z oficjalnych pieczęci ok. 945 r. spowodowane było nie tyle jej śmiercią, ile względami natury politycznej, tj. pozbawieniem rodu Lekapenów władzy w Konstantynopolu oraz objęciem samodzielnych rządów przez Konstantyna VII Porfirogenetę. Nie można jednak wykluczyć i tej możliwości, iż rzeczywiście Maria rozstała się z życiem wcześniej. Por. Runciman, The Emperor, s. 237; Shepard, A marriage too far, s. 147-148; Leszka, Wizerunek, s. 128; Leszka - Marinow, Carstwo butgarskie, s. 160.

${ }^{18}$ Co ciekawe, wspomniane panie były ze sobą spokrewnione, wywodząc się od wspólnego przodka - cesarza Romana I Lekapena. Maria była córką jego syna Krzysztofa, zaś Anna - dzieckiem Romana II, którego Konstantynowi VII Porfirogenecie urodziła Helena Lekapena, córka Romana I. Marię należałoby zatem uważać za wujeczną ciotkę Anny. 


\begin{tabular}{|c|c|c|}
\hline $\begin{array}{c}\text { OKOLICZNOŚCI } \\
\text { ZAWARCIA } \\
\text { MAŁŻEŃSTWA ZE } \\
\text { SŁOWIAŃSKIM } \\
\text { WŁADCĄ }\end{array}$ & $\begin{array}{l}927 \text { r. Zostaje zawarty pokój między } \\
\text { Bułgarią i Bizancjum, którego trwałość } \\
\text { ma gwarantować małżeństwo Piotra } \\
\text { z Marią. Ich ślub odbywa się w Kon- } \\
\text { stantynopolu, z udziałem patriarchy } \\
\text { Stefana, najwyższych dostojników ce- } \\
\text { sarstwa i posłów bułgarskich. Bizan- } \\
\text { cjum uznaje prawo Piotra do noszenia } \\
\text { tytułu bazyleusa (cesarza/cara) Bułga- } \\
\text { rów. Kościół bułgarski zyskuje autoke- } \\
\text { falię, a jego głowa - godność patriarchy. }\end{array}$ & $\begin{array}{l}\text { 988/989 r. Cesarz Bazyli II prosi Wło- } \\
\text { dzimierza o pomoc w walce z uzurpato- } \\
\text { rem, Bardasem Fokasem. Książę ruski } \\
\text { godzi się w zamian za obietnicę ręki } \\
\text { Anny. Warunkiem jest przyjęcie chrztu. } \\
\text { Po zwycięstwie nad Bardasem, Bazyli II } \\
\text { próbuje wycofać się z obietnicy. Książę, } \\
\text { by wymusić jej spełnienie, uderza na po- } \\
\text { siadłości bizantyńskie na Krymie (Cher- } \\
\text { sonez Taurydzki). Anna zostaje wysłana } \\
\text { do nowo ochrzczonego męża. Powstaje } \\
\text { Kościół ruski: metropolia kijowska pod- } \\
\text { legła patriarsze Konstantynopola. }\end{array}$ \\
\hline $\begin{array}{c}\text { STATUS } \\
\text { POPRZEDNICZEK } \\
\text { NA TRONIE }\end{array}$ & $\begin{array}{l}\text { Żona bułgarskiego władcy nie jest } \\
\text { wymieniana w oficjalnych dokumen- } \\
\text { tach. Zazwyczaj nie znamy nawet jej } \\
\text { imienia. Do X w. nie pojawia się po- } \\
\text { stać kobiety wpływowej politycznie, } \\
\text { samodzielnie sprawującej władzę lub } \\
\text { regencję }{ }^{19} \text {. }\end{array}$ & $\begin{array}{l}\text { Księżna wymieniana jest niekiedy } \\
\text { z imienia w oficjalnych dokumentach, } \\
\text { np. w tekście układu bizantyńsko- } \\
\text {-ruskiego z } 944 \text { r. poseł władczyni } \\
\text { wspomniany jest na trzecim miejscu } \\
\text { (po posłach księcia i następcy tronu }{ }^{20} \text {. } \\
\text { W X w. księżna Olga formalnie spra- } \\
\text { wuje regencję, de facto rządząc jak sa- } \\
\text { modzielny, pełnoprawny władca. }\end{array}$ \\
\hline $\begin{array}{c}\text { PRZEKAZ ŹRÓDEL } \\
\text { BIZANTYŃSKICH }\end{array}$ & $\begin{array}{l}\text { O ślubie Marii i Piotra wspomina wie- } \\
\text { le źródeł bizantyńskich. Dysponuje- } \\
\text { my szczegółowym opisem wydarzeń, } \\
\text { towarzyszących podpisaniu pokoju } \\
\text { i zawarcia małżeństwa. Kontynuacja } \\
\text { Teofanesa zawiera wzmianki o wizy- } \\
\text { tach carycy w Konstantynopolu. Teksty } \\
\text { bizantyńskie nie informują zaś o dzia- } \\
\text { łalności Marii w Bułgarii. }\end{array}$ & $\begin{array}{l}\text { W źródłach bizantyńskich nie odnaj- } \\
\text { dziemy nieomal żadnej informacji } \\
\text { o ślubie Anny i Włodzimierza oraz } \\
\text { o działalności Porfirogenetki na Rusi. } \\
\text { Jan Skylitzes, a w ślad za nim Zona- } \\
\text { ras, informują lakonicznie, iż Bazyli } \\
\text { II uczynił Włodzimierza swoim szwa- } \\
\text { grem, mężem Anny, potrzebując jego } \\
\text { pomocy wojskowej }{ }^{21} \text {. Mariaż ten był } \\
\text { zapewne wstydliwym wydarzeniem } \\
\text { z punktu widzenia Konstantynopola. }\end{array}$ \\
\hline
\end{tabular}

${ }^{19}$ Por. Христодулова, Титул, s. 142; Игнатов, Българските ияарищи, s. 9-12; Георгиева, Жената, s. 312; Leszka - Marinow, Carstwo butgarskie, s. 206-207.

${ }^{20}$ Por. Лаврентьевская летопись, ed. И.Ф. Карский, Полное собрание русских летописей 1, Ленинград 1926-1928, 47, tłum. F. Sielicki: Powieść minionych lat. Najstarsza kronika kijowska, Wrocław 2005, 41: „Roku 6453 (945) [...] Odpis z umowy, zawartej za cesarzy: Romana, Konstantyna i Stefana, miłujących Chrystusa władców. My od rodu ruskiego posłowie i kupcy, Iwor, poseł Igora, wielkiego kniazia ruskiego, i ogólni posłowie: Wujefast od Światosława, syna Igorowego; Iskusewi od kniahini Olgi".

${ }^{21}$ Por. Joannes Scylitzes, Synopsis historiarum XVI 17, CFHB (Series Berolinensis) 5, s. 336, tłum. A. Kotłowska: Jan Skylitzes, Zarys historii, w: Testimonia najdawniejszych dziejów Stowian. Seria grecka, z. 6: Pisarze wieku XI, red. A. Kotłowska - A. Brzóstkowska, Warszawa 2013, 196-197: „Wezwał ich [Rusów - Z.B.] na mocy sojuszu, uczyniwszy ich archonta Włodzimierza szwagrem przez swoją siostrę Annę". Zob. Joannes Zonaras, Epitomae historiarum XVII 7, CSHB [31], s. 553. 


\begin{tabular}{|c|c|c|}
\hline $\begin{array}{c}\text { PRZEKAZ ŹRÓDEL } \\
\text { RODZIMYCH }\end{array}$ & $\begin{array}{l}\text { Źródła bułgarskie nie wspominają } \\
\text { o Marii i jej działalności w Presławiu. } \\
\text { Symptomatyczny jest pod tym wzglę- } \\
\text { dem przekaz Bułgarskiej kroniki apo- } \\
\text { kryficznej - utworu kompilacyjnego } \\
\text { z XII w. Według autora tego zabytku, } \\
\text { car Piotr żył i rządził „bezżennie”22. }\end{array}$ & $\begin{array}{l}\text { Wzmianki o Annie pojawiają się w źró- } \\
\text { dłach ruskich, np. Powieści minionych } \\
\text { lat (pocz. XII w.). Tamtejsza tradycja } \\
\text { pamięta o jej cesarskim pochodzeniu: } \\
\text { w tekstach jest ona określana jako ca- } \\
\text { rewna, na wyobrażeniach ikonograficz- } \\
\text { nych okrywają ją purpurowe szaty. Nie } \\
\text { ulega wątpliwości wpływ księżnej na } \\
\text { konwersję Włodzimierza i chrystiani- } \\
\text { zację Rusi. Rolę mulier suadens pełni } \\
\text { tu jednak nie ona, lecz babka Włodzi- } \\
\text { mierza - Olga }{ }^{23} \text {. }\end{array}$ \\
\hline $\begin{array}{c}\text { PRZEKAZ ŹRÓDEL } \\
\text { OBCYCH }\end{array}$ & $\begin{array}{l}\text { O ślubie Marii i Piotra w kontekście za- } \\
\text { warcia pokoju z } 927 \text { r. pisze Liutprand } \\
\text { z Cremony. W Antapodosis wspomina } \\
\text { też o tym, iż Lekapena zmieniła imię na } \\
\text { Irena (Pokój). Nie podaje jednak żad- } \\
\text { nych informacji na temat późniejszej } \\
\text { działalności carycy w Bułgarii }{ }^{24} \text {. }\end{array}$ & $\begin{array}{l}\text { Okoliczności zawarcia małżeństwa mię- } \\
\text { dzy Anną a księciem ruskim szczegó- } \\
\text { łowo relacjonuje w swej kronice Jahia } \\
\text { zAntiochii (ok. 975-1066), chrześcijanin } \\
\text { (melkita) piszący po arabsku. Wspomina } \\
\text { o wkładzie księżnej w chrystianizację } \\
\text { Rusi, tj. o ufundowaniu przez nią wielu } \\
\text { świątyń }{ }^{25} \text {. Historyk arabski Abu Shudja } \\
\text { al-Rudhrawari (1045-1095), przypisuje } \\
\text { Annie kluczową rolę w nawróceniu Wło- }\end{array}$ \\
\hline
\end{tabular}

Najnowszy przegląd źródeł bizantyńskich, zawierających informacje na temat chrystianizacji Rusi, znajdzie Czytelnik w pracy: М.В. Бибиков, Byzantinorossica. Свод византийских свидетельств о Руси, t. 1, Москва 2004, 57-67.

${ }^{22}$ Por. Butgarska kronika apokryficzna. Stowo proroka Izajasza o tym, jak zostat przez anioła wyniesiony do siódmego nieba, tłum. M. Skowronek, w: Apokryfy i legendy starotestamentowe Stowian Południowych, red. G. Minczew - M. Skowronek, Kraków 2006, 65-66: „Po jego śmierci przejął Carstwo Bułgarskie syn jego car Piotr, który był władcą Bułgarom i Grekom. Panował on w Ziemi Bułgarskiej dwanaście lat, bezgrzesznie i bezżennie, a carstwo jego było błogosławione". Na temat specyfiki gatunkowej i przekazu ideowego źródła zob. K. Marinow, Kilka uwag na temat ideologiczno-eschatologicznej wymowy Butgarskiej kroniki apokryficznej, „Fundamenta Europaea” 6/7 (2007) 61-75.

${ }^{23}$ Nowe spojrzenie na rolę Anny w upowszechnianiu chrześcijaństwa na Rusi prezentuje w swych monografiach badaczka ukraińska, Nadieżda Nikitienko. Zauważa, że wkład księżnej w przeszczepianie na grunt wschodniosłowiański nowej religii oraz elementów kultury bizantyńskiej mógł być znacznie większy, niż przyjęto sądzić w dotychczasowej historiografii. Uczona analizuje też mechanizmy, które doprowadziły do „wyrugowania” Anny ze staroruskiej tradycji hagiograficznej i nadania statusu krzewicielki chrześcijaństwa babce Włodzimierza, księżnej Oldze. Por. Н.Н. Никитенко, Русь и Византия в монументальном комплексе Софии Киевской. Историческая проблематика, Киев 2004, spec. s. 36-88 і 341-352; taż, София Киевская и ее создатели, Каменец-Подольский 2014, spec. s. 229-241. Wątek Anny jako mulier suadens w tradycji ruskiej podjął ostatnio G. Pac, Kobiety w dynastii Piastów. Rola spoleczna piastowskich żon i córek do połowy XII w. - studium porównawcze, Torun 2013, 42-61.

${ }^{24}$ Por. Liudprandus Cremonensis, Relatio de legatione constantinopolitana 16, 19, ed. P. Chiesa, CCCM 156, 194-195; tenże, Antapodosis III 38, CCCM 156, 86.

${ }^{25}$ Por. Histoire de Yahya-ibn-Sa Ïd d'Antioche, continuateur de Sa Ïd-ibn-Bitriq, ed. I. Kratchkovsky - A. Vasiliev, II, PO 23/3, Paris 1932, 423. 


\begin{tabular}{|c|c|c|}
\hline & & $\begin{array}{l}\text { dzimierza - jej odmowa poślubienia in- } \\
\text { nowiercy miała skłonić księcia do przy- } \\
\text { jęcia chrztu }{ }^{26} \text {. }\end{array}$ \\
\hline $\begin{array}{l}\text { SFERA OFICJALNA } \\
\text { (ZMIANA ZA } \\
\text { PANOWANIA } \\
\text { BIZANTYNKI) }\end{array}$ & 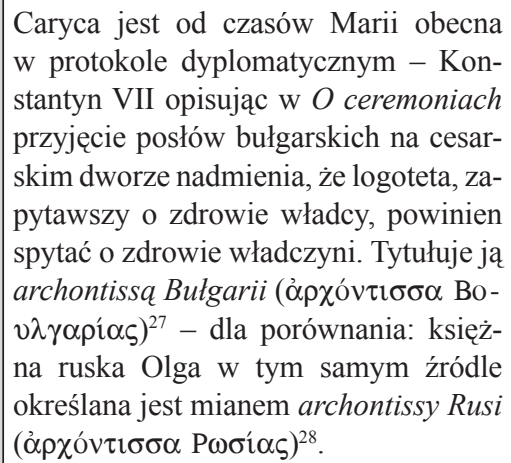 & $\begin{array}{l}\text { Księżna była wspominana najprawdo- } \\
\text { podobniej w intytulacjach dokumen- } \\
\text { tów ruskich. Tzw. krótka redakcja Sta- } \\
\text { tutu (ustawu) kościelnego Włodzimie- } \\
\text { rza (przełom X/XI w.), regulującego } \\
\text { szereg kwestii związanych z funkcjo- } \\
\text { nowaniem Kościoła ruskiego, zawiera } \\
\text { formułę, iż książę podjął wymienio- } \\
\text { ne w akcie decyzje po konsultacjach } \\
\text { z Anną }{ }^{29} \text {. }\end{array}$ \\
\hline PIECZĘCIE & $\begin{array}{l}\text { Maria pojawia się na pieczęciach Pio- } \\
\text { tra z lat } 927-945 \text {. Na artefaktach tych } \\
\text { odnajdujemy jej wizerunek. Niekiedy } \\
\text { jest również wymieniona z imienia } \\
\text { w inskrypcjach. Po } 945 \text { r. na pieczę- } \\
\text { ciach Piotr jest przedstawiany sam. }\end{array}$ & $\begin{array}{l}\text { Nie zachowała się ani jedna pieczęć } \\
\text { księcia Włodzimierza. Istnieją jedynie } \\
\text { artefakty, które badacze próbują przypi- } \\
\text { sywać temu władcy. Nie pojawia się na } \\
\text { nich ani imię, ani wizerunek Anny. Nie } \\
\text { zachowało się też jej sigillum privatum, } \\
\text { w przeciwieństwie do pieczęci innych } \\
\text { księżnych ruskich bizantyńskiego po- } \\
\text { chodzenia, np. Marii Monomach }{ }^{30} \text {. }\end{array}$ \\
\hline MONETY & $\begin{array}{l}\text { Istnieje kilka srebrnych monet, które } \\
\text { niektórzy badacze próbują przypisy- } \\
\text { wać carowi Piotrowi - Maria się na } \\
\text { nich nie pojawia. }\end{array}$ & $\begin{array}{l}\text { Anna nie pojawia się na ani jednej } \\
\text { z wielu zachowanych złotych i srebr- } \\
\text { nych monet księcia Włodzimierza. Na } \\
\text { numizmatach tych występuje tylko wy- } \\
\text { obrażenie tronującego księcia }^{31} \text {. }\end{array}$ \\
\hline
\end{tabular}

${ }^{26}$ Por. Continuation of the Experiences of the Nations by Abu Shuja'Rudhrawari, Vizier of Muqtadi and Hilal b. Muhassin, Vizier's secretary in Baghdad, thum. D.S. Margoliouth, w: The Eclipse of the Abbasid Caliphate. Original Chronicles of the Fourth Islamic Century, ed. H.F. Amedroz D.S. Margoliouth, t. 6, London 1921, 118-119.

${ }^{27}$ Por. Constantinus Porphyrogenitus, De caeremoniis aulae byzantinae II 47, ed. I.I. Reiske, CSHB [7], Bonnae 1829, 681-682; Христодулова, Титул, s. 142; Leszka - Marinow, Carstwo butgarskie, s. 206-207.

${ }^{28}$ Por. Constantinus Porphyrogenitus, De caeremoniis aulae byzantinae II 15, CSHB [7], s. 594.

${ }^{29}$ Por. Я.Н. Щапов, Княжеские уставы и иеерковь в Древней Руси XI-XIV вв., Москва 1972, 115-127; tenże, Древнерусские княжеские уставы XI-XV вв., Москва 1976, 66. Podsumowanie dyskusji na temat kwestii autentyczności Statutu (ustawu) kościelnego Włodzimierza oraz wybór literatury przedmiotu zob. G. Podskalsky, Chrześcijaństwo i literatura teologiczna na Rusi Kijowskiej (988-1237), tłum. J. Zychowicz, Kraków 2000, 270-272.

${ }^{30}$ Рог. В.Л. Янин, Актовые печати Древней Руси X-XV вв., t. 1: Печати X-начала ХІІІ в., Москва 1970, 17-19 і 170.

${ }^{31}$ Por. Сотникова - Спасский, Тысячелетие, s. 60-81 і 115-180. 
W świetle powyższej analizy Maria jawi się jako osoba pozbawiona realnego wpływu na posunięcia polityczne swego męża. Co więcej, żadne z zachowanych źródeł nie wspomina o jej aktywności w życiu publicznym. Nie odnajdujemy śladów samodzielnych działań carycy nawet w sferze zachowań tradycyjnie przypisanych chrześcijańskiej władczyni: nie słyszymy - jak ma to chociażby miejsce w przypadku księżnych ruskich z tego samego okresu, Olgi i Anny - o jej działalności fundacyjnej, dobroczynnej, czy też mającej na celu propagowanie i umacnianie chrześcijaństwa. Źródła wszelkiego rodzaju i proweniencji wspominają o niej przeważnie w kontekście układu pokojowego z 927 roku.

Można odnieść wrażenie, iż zamieszczenie wizerunku i imienia małżonki cara na jego pieczęciach z lat 927-945 również nie jest efektem osobistych starań Lekapeny, ani odzwierciedleniem statusu faktycznej współwładczyni Piotra, jakim - zdaniem niektórych badaczy - miała się ona cieszyćc ${ }^{32}$. Najprawdopodobniej rację mają ci uczeni, którzy skłonni są postrzegać wspomniane pieczęcie raczej jako artefakty o charakterze kommemoratywnym i propagandowym, wykonane w celu upamiętnienia pokoju z $927 \mathrm{r}$. i podkreślenia znaczenia tego wydarzenia dla państwa bułgarskiego i jego władcy ${ }^{33}$. Mogły być one także narzędziem legitymizacji tytułu carskiego Piotra. Marii, wnuczce bizantyńskiego bazyleusa, przypadałaby tu rola dość biernej przekazicielki cesarskiej godności - to dzięki małżeństwu z nią bułgarski monarcha zyskiwał formalne prawo do tytułowania się carem $^{34}$.

Warto zwrócić uwagę na jeszcze jeden fakt - imię i wizerunek carycy znikają z pieczęci Piotra po 945 r., a więc wtedy, gdy od władzy w Konstantynopolu zostaje odsunięty ród Lekapenów i rozpoczyna się samodzielne panowanie niechętnego zarówno im samym, jak i mariażowi bizantyńsko-bułgarskiemu, Konstantyna VII Porfirogenety ${ }^{35}$. Można więc odnieść wrażenie, iż zarówno włączenie Marii do systemu autoprezentacji władcy w Bułgarii w 927 r., jak i jej usunięcie w 945 r., podyktowane było wymogami polityki zagranicznej i dyplomacji: w obu przypadkach stanowiło to ukłon pod adresem aktualnie władającego nad Bosforem bazyleusa ${ }^{36}$.

Do sfery historiograficznego mitu należy również odesłać tezę o szeroko zakrojonej bizantynizacji starobułgarskiej kultury politycznej za panowania Piotra i Marii. Jak słusznie podkreśla Jonathan Shepard, Bułgaria znalazła się w orbicie wpływów cywilizacji wschodniochrześcijańskiej o wiele wcześniej,

\footnotetext{
${ }^{32}$ Por. Georgieva, The Byzantine Princesses, s. 168; Йорданов, Корпус на печатите, s. 59; Георгиева, Жената, s. 313-314.

${ }^{33}$ Por. Божилов - Гюзелев, История, s. 276; Leszka - Marinow, Carstwo butgarskie, s. 159.

${ }^{34}$ Por. Йорданов, Корпус на печатите, s. 59; Георгиева, Жената, s. 314; Николов, Политическа мисъл, s. 239; Leszka - Marinow, Carstwo butgarskie, s. 159.

${ }^{35}$ Por. Runciman, The Emperor, s. 229-237; Тодоров, Константин Багренородни, s. 396397; Николов, Политическа мисъл, s. 269-278.

${ }^{36}$ Por. Йорданов, Корпус на печатите, s. 63; Leszka - Marinow, Carstwo butgarskie, s. 160.
} 
a recepcja elementów tradycji bizantyńskiej była tu procesem długotrwałym ${ }^{37}$. Spośród wschodniorzymskich kompilacji prawnych, przetłumaczonych na język staro-cerkiewno-słowiański i przyswojonych w pierwszym państwie bułgarskim, jedynie całościowy przekład Eklogi można uznać za dokonanie z okresu rządów Piotra. Sporządzono go najprawdopodobniej w Presławiu po roku $950^{38}$. Oba warianty bizantyńskiego Nomokanonu (Nomokanon 50 Rozdziałów i Nomokanon 14 Rozdziałów) zaadaptowano tu natomiast już wcześniej, za panowania Symeona I Wielkiego $(893-927)^{39}$. Z okresu przed wstąpieniem Piotra na tron pochodzi też inny, funkcjonujący na interesującym nas obszarze, zbiór praw, tj. Zakon sudnyj ljudem ${ }^{40}$.

$\mathrm{Na}$ czas rządów Piotra datuje się również niekiedy w literaturze przedmiotu powstanie najstarszego staro-cerkiewno-słowiańskiego tłumaczenia traktatu Schede basilike autorstwa konstantynopolitańskiego diakona Agapeta (VI w.). Ten niewielkich rozmiarów utwór, zawierający syntetyczne omówienie najważniejszych założeń wschodniorzymskiej teorii władzy cesarskiej oraz wizję idealnego chrześcijańskiego monarchy, zyskał, poczynając od X-XI w., znaczną popularność na obszarze Slavia Orthodoxa, stając się podstawowym medium, za pośrednictwem którego dokonała się recepcja elementów bizantyńskiego modelu władzy w Bułgarii, na Rusi, a w okresie późniejszym

${ }^{37}$ Por. Shepard, A marriage too far, s. 140.

${ }^{38}$ Por. F. Dvornik, Byzantine Political Ideas on Kievian Russia, DOP 9-10 (1956) 81 i 89; Т. Славова, Юридическа литература, w: История на българската средновековна литература, ред. А. Милтенова, София 2008, 196.

${ }^{39}$ Por. Dvornik, Byzantine Political Ideas, s. 80; Я.Н. Щапов, Номоканон Иоанна Схоластика и Синтагма 14 титулов у Славян в IX-X вв., w: Beiträge zur byzantinischen Geschichte im 9.-11. Jahrhundert. Akten des Colloquiums Byzanz auf dem Höhepunkt seiner Macht, Liblice, 22.-23. September 1977, hrsg. von V. Vavřinek, Praha 1978, 394; Славова, Юридическа литература, s. 195.

${ }^{40}$ Przekład Schede basilike na język staro-cerkiewno-słowiański oraz jego wpływ na ideologię polityczną państwowości Słowian prawosławnych jest zagadnieniem zasługującym na odrębne omówienie i posiadającym dość znaczną literaturę przedmiotu: В. Вальденберг, Наставление писателя VI в. Агапита в русской письменности, „Византийский Временник” 24 (1926) 27-34; P. Henry, A Mirror for Justinian: The Ekthesis of Agapetus Diaconus, GRBS 8 (1967) 281-308; J. Irmscher, Das Bild des Untertanen im Fürstenspiegel des Agapetos, „Klio” 60 (1978) 507-509; I. Ševčenko, Agapetus East and West: the Fate of a Byzantine „, Mirror of Princes”, w: Ideology, Letters and Culture in the Byzantine World, London 1982, 3-44; М.Т. Дьячок, О месте и времени первого славянского перевода „Наставления” Агапита, w: Памятники литературы и общественной мысли эпохи феодализма, ред. Е.К. Ромодановская, Новосибирск 1985, 5-13; I. Ševčenko, „Ljubomudrějšij Kÿr" Agapit Diakon: On a Kiev Edition of a Byzantine „Mirror of Princes”, w: Byzantium and the Slavs in Letters and Culture, Cambridge - Napoli 1991, 497-557; tenże, A Neglected Byzantine Source of Muscovite Political Ideology, w: Byzantium and the Slavs, s. 4987; tenże, On Some Sources of Prince Svjatoslav's Izbornik of the Year 1076, w: Byzantium and the lavs, s. 241-261; А. Николов, Старобългарският превод на „Изложение на поучителни глави към император Юстиниан” от дякон Агапит и развитието на идеята за достойнството на българския владетел в края на IX - началото на X в., „Palaeobulgarica” 24 (2000) fasc. 3, 76105 (kompletna edycja tekstu staro-cerkiewno-słowiańskiego: 93-100); С. Марјановић-Душанић, 
- także w Serbii ${ }^{41}$. Angeł Nikołow, w monografii poświęconej starobułgarskiej ideologii politycznej, wykazał jednak, iż zarówno okoliczności historyczne, wymowa ideowa zabytku, jak i cechy lingwistyczne jego staro-cerkiewno-słowiańskiego przekładu, wskazują na to, iż nie został on przyswojony na gruncie kultury bułgarskiej za panowania Piotra, ale już wcześniej - za rządów jego ojca, Symeona ${ }^{42}$.

Reasumując, trudno uznać Marię i jej małżonka za inicjatorów bizantynizacji kultury X-wiecznej Bułgarii. Jak widać, kontynuowali oni dzieło poprzedników Piotra, stąpając szlakiem wytyczonym przede wszystkim przez cara Symeona. Należy jednak podkreślić, że fakt, iż w 927 r. Lekapena przybyła na dwór, który był już dość dobrze zaznajomiony z cywilizacją bizantyńską, nie wyklucza możliwości jej osobistego oddziaływania na nowe otoczenie - najprawdopodobniej starała się zaszczepić w Presławiu obyczaje i elementy ceremoniału, znane jej z pałacu w Konstantynopolu, nie dysponujemy jednak wystarczającym materiałem źródłowym, by określić, jakie sfery obejmował jej wpływ. Najprawdopodobniej jednak nie wyszedł on poza mury carskiej siedziby i wąski krąg jej najbliższego otoczenia.

Rex Imago Dei: о српској преради Агапитовог огледала, w: Трећа југословенска конферениија византолога, Крушеваи, 10-13 мај 2000, Београд - Крушевац 2002, 135-148; Николов, Политическа мисъл, s. 214-230 і 250-268; P.N. Bell, Agapetus - „Advice“: his Sources, Methods and Thought, w: Three Political Voices from the Age of Justinian. Agapetus, „Advice to the Emperor”. „Dialogue on Political Science”. Paul the Silentiary, „Description of Hagia Sophia”, ed. P.N. Bell, Liverpool 2009, 27-46; Z. Brzozowska, ,, Schede basilike” konstantynopolitańskiego diakona Agapeta i jego wplyw na myśl politycznq średniowiecznej Rusi, „Acta Universitatis Lodziensis. Folia historica” 87 (2011) 329-342; A. Kompa, Mieszkańcy Konstantynopola w oczach intelektualistów miejscowej proweniencji, w: A. Kompa - M.J. Leszka - T. Wolińska, Mieszkańcy stolicy świata. Konstantynopolitańczycy między starożytnościq a średniowieczem, Byzantina Lodziensia 17, Łódź 2014, 41-42. ${ }^{38}$ Por. F. Dvornik, Byzantine Political Ideas on Kievian Russia, DOP 9-10 (1956) 81 і 89; Т. Славова, Юридическа литература, w: История на българската средновековна литература, ред. А. Милтенова, София 2008, 196.

${ }^{42}$ Por. Николов, Старобългарският превод, s. 77; Николов, Политическа мисъл, s. $214-$ 230 i $253-269$. 


\section{THE ROLE OF EMPRESS MARIA-IRENE LEKAPENE IN THE RECEPTION OF THE ELEMENTS OF BYZANTINE MODEL OF POWER IN THE FIRST BULGARIAN STATE}

\section{(Summary)}

Maria Lekapene was the granddaughter of Byzantine Emperor Romanos I Lekapenos. In 927 she married Peter I of Bulgaria. Her marriage in Constantinople aimed to strengthen the newly signed Byzantine-Bulgarian peace treaty. Historians attributed to the Empress a significant impact on the political moves of her husband. The Empress was also to introduce a lot of elements of the Byzantine theory of power in Bulgaria and even to play the role of spy of Constantinople at the Preslav court. These views have not been corroborated in surviving source material. The Byzantine authors, who provided a lot of information about the wedding of Maria and Peter, did not write anything about the subsequent behavior of the Empress in her new homeland. The political activity of the wife of Peter is not mentioned in indigenous Bulgarian sources or foreign ones (e.g. Liutprand of Cremona). The thesis that Maria wielded real political power can be confirmed only in sigillographic materials. In 927-945 the Bulgarian ruler was always represented on his own official seals accompanied by his wife. However it was not a reflection of her status as a real co-emperor. These seals were propagandic artifacts which were made to commemorate the peace of 927 . The seals could also be seen as a tool legitimizing the imperial title of Peter. It is hard to consider Mary as the initiator of the Byzantinization of the culture of tenth-century Bulgaria. In 927 Lekapene arrived at the court, which was already quite familiar with the Byzantine civilization. This does not exclude the possibility of her personal impact on the new court. However, most likely the impact did not go beyond the walls of the Emperor's headquarters.

Key words: Maria-Irene Lekapene, Peter I of Bulgaria, First Bulgarian State, Byzantine-Bulgarian relations, peace treaty of 927, Byzantine political thought, Byzantine influence on Old Bulgarian culture.

Słowa kluczowe: Maria-Irena Lekapena, Piotr I, pierwsze państwo bułgarskie, stosunki bizantyńsko-bułgarskie, pokój z 927 r., bizantyńska myśl polityczna, wpływ bizantyński na kulturę starobułgarską.

\section{BIBLIOGRAFIA}

\section{Źródła}

Bułgarska kronika apokryficzna. Stowo proroka Izajasza o tym, jak został przez anioła wyniesiony do siódmego nieba, tłum. M. Skowronek, w: Apokryfy i legendy starotestamentowe Słowian Południowych, red. G. Minczew - M. Skowronek, Kraków 2006, 62-69.

Constantinus Porphyrogenitus, De administrando imperio, ed. G. Moravcsik, CFHB 1, Washington 1967. 
Constantinus Porphyrogenitus, De caeremoniis aulae byzantinae, ed. I.I. Reiske, CSHB [7], Bonnae 1829.

Continuation of the Experiences of the Nations by Abu Shuja'Rudhrawari, Vizier of Muqtadi and Hilal b. Muhassin, Vizier's secretary in Baghdad, thum. D.S. Margoliouth, w: The Eclipse of the Abbasid Caliphate. Original Chronicles of the Fourth Islamic Century, ed. H.F. Amedroz - D.S. Margoliouth, t. 6, London 1921.

Georgius Monachus, Vitae imperatorum recentiorum, ed. I. Bekker, CSHB [48], Bonnae $1838,761-924$.

Histoire de Yahya-ibn-Sa '̈d d'Antioche, continuateur de Sa Ïd-ibn-Bitriq, ed. I. Kratchkovsky - A. Vasiliev, II, PO 23/3, Paris 1932, 347-520.

Joannes Scylitzes, Synopsis historiarum, ed. I. Thurn, CFHB (Series Berolinensis) 5, Berolini 1973, tłum. A. Kotłowska: Jan Skylitzes, Zarys historii, w: Testimonia najdawniejszych dziejów Słowian. Seria grecka, z. 6: Pisarze wieku XI, red. A. Kotłowska - A. Brzóstkowska, Warszawa 2013, 106-269.

Joannes Zonaras, Epitomae historiarum, ed. Th. Büttner-Wobst, CSHB [31], Bonnae 1897.

Leo Grammaticus, Chronographia, ed. I. Bekker, CSHB [34], Bonnae 1842.

Liudprandus Cremonensis, Antapodosis, ed. Chiesa, CCCM 156, Turnholti 1998, 5-150.

Liudprandus Cremonensis, Relatio de legatione constantinopolitana, ed. Chiesa, CCCM 156, Turnholti 1998, 185-218.

Symeon Magister et Logotheta, Chronicon, rec. S. Wahlgren, CFHB (Series Berolinensis) 44/1, Berolini - Novi Eboraci 2006.

Theophanes Continuatus, ed. I. Bekker, CSHB [48], Bonnae 1838, 1-481.

Лаврентьевская летопись, ed. И.Ф. Карский, Полное собрание русских летописей 1 , Ленинград 1926-1928, tłum. F. Sielicki: Powieść minionych lat. Najstarsza kronika kijowska, Wrocław 2005.

\section{Opracowania}

Bell P.N., Agapetus - „Advice“: his Sources, Methods and Thought, w: Three Political Voices from the Age of Justinian. Agapetus, ,Advice to the Emperor”. „,Dialogue on Political Science”. Paul the Silentiary, ,Description of Hagia Sophia”, ed. P.N. Bell, Liverpool 2009, 27-46.

Brzozowska Z., ,Schede basilike” konstantynopolitańskiego diakona Agapeta i jego wpływ na myśl politycznq średniowiecznej Rusi, ,Acta Universitatis Lodziensis. Folia historica" 87 (2011) 329-342.

Dvornik F., Byzantine Political Ideas on Kievian Russia, DOP 9-10 (1956) 73-121.

Georgieva S., The Byzantine Princesses in Bulgaria, „Byzantinobulgarica” 9 (1995) 163-201.

Grierson Ph., Byzantine Coins, London - Berkeley - Los Angeles 1982.

Henry P., A Mirror for Justinian: The Ekthesis of Agapetus Diaconus, GRBS 8 (1967) 281-308.

Irmscher J., Das Bild des Untertanen im Fürstenspiegel des Agapetos, „Klio” 60 (1978) 507-509.

Jordanov I., Corpus of Byzantine Seals from Bulgaria, t. 3/1, Sofia 2009.

Kompa A., Mieszkańcy Konstantynopola w oczach intelektualistów miejscowej proweniencji, w: A. Kompa - M.J. Leszka - T. Wolińska, Mieszkańcy stolicy świata. Konstantynopolitańczycy między starożytnościq a średniowieczem, Byzantina Lodziensia 17, Łódź 2014, 3-306. 
LeSZKa M.J., Wizerunek władców pierwszego państwa bułgarskiego w bizantyńskich źródłach pisanych (VIII - pierwsza połowa XII w.), Byzantina Lodziensia 7, Łódź 2003.

Leszka M.J. - Marinow K., Carstwo bułgarskie. Polityka - społeczeństwo - gospodarka - kultura. 866-971, Warszawa 2015.

Maksimovich K., Byzantine Law in Old Slavonic Translations and the Nomocanon of Methodius, „Byzantinoslavica” 65 (2007) 9-18.

Marinow K., In the Shackles of the Evil One. The Portrayal of Tsar Symeon I the Great (893-927) in the Oration On the treaty with the Bulgarians, „Studia Ceranea” 1 (2011) 157-190.

MARINOw K., Kilka uwag na temat ideologiczno-eschatologicznej wymowy Bułgarskiej kroniki apokryficznej, „Fundamenta Europaea” 6/7 (2007) 61-75.

Marinow, Peace in the House of Jacob. A Few Remarks on the Ideology of Two Biblical Themes in the Oration On the Treaty with the Bulgarians, „Bulgaria Mediaevalis" 3 (2012) 85-93.

Oiкonomides N., A Collection of Dated Byzantine Lead Seals, Washington 1986.

PAC G., Kobiety $w$ dynastii Piastów. Rola społeczna piastowskich żon i córek do połowy XII w. - studium porównawcze, Toruń 2013.

Podskalsky G., Chrześcijaństwo i literatura teologiczna na Rusi Kijowskiej (988-1237), tłum. J. Zychowicz, Kraków 2000.

Runciman S., The Emperor Romanus Lecapenus and His Reign. A Study of Tenth-Century Byzantium, Cambridge 1969.

ShePARD J., A marriage too far? Maria Lekapena and Peter of Bulgaria, w: The Empress Theophano. Byzantium and the West at the turn of the first millennium, ed. A. Davids, Cambridge 1995, 121-149.

ŠEvČEnko I., Agapetus East and West: the Fate of a Byzantine „,Mirror of Princes”, w: Ideology, Letters and Culture in the Byzantine World, London 1982, 3-44.

ŠevčEnKo, ,Ljubomudrějšij Kÿr” Agapit Diakon: On a Kiev Edition of a Byzantine „, Mirror of Princes", w: Byzantium and the Slavs in Letters and Culture, Cambridge - Napoli 1991, 497-557.

ŠEvČEnKo, A Neglected Byzantine Source of Muscovite Political Ideology, w: Byzantium and the Slavs in Letters and Culture, Cambridge - Napoli 1991, 49-87.

ŠEvčEnko, On Some Sources of Prince Svjatoslav's Izbornik of the Year 1076, w: Byzantium and the Slavs in Letters and Culture, Cambridge - Napoli 1991, 241-261.

VAšıcA J., K otázce puvodu Zakona sudného ljudem, „Slavia” 30 (1961) 1-19.

WolińsKa T., Konstantynopolitańska misja Liutpranda z Kremony (968), w: Cesarstwo bizantyńskie. Dzieje. Religia. Kultura. Studia ofiarowane Profesorowi Waldemarowi Ceranowi przez uczniów na 70-lecie Jego urodzin, red. P. Krupczyński - M.J. Leszka, Łask - Łódź 2006, 201-223.

Биьиков М.В., Byzantinorossica. Свод византийских свидетельств о Руси, t. 1, Москва 2004.

Божилов И. - ГюзЕЛЕв В., История на средновековна България. VII-XIV в., София 2006.

ВАльденБерг В., Наставление писателя VI в. Агапита в русской письменности, „Византийский Временник” 24 (1926) 27-34.

ГеоргиевА С., Жената в българското средновековие, Пловдив 2011.

ГюзЕЛев В., Значението на брака на цар Петър (927-969) с ромейката Мария-Ирина Лакапина (911-962), w: Културните текстове на миналото-носители, символи, идеи, t. 1, Текстовете на историята, история на текстовете. Материали от 
Юбилейната международна конференщия в чест на 60-годишнината на проф. д.и.н. Казимир Попконстантинов, Велико Търново, 29-31 октомври 2003 г., София 2005, 27-33.

Дьячок М.Т., О месте и времени первого славянского перевода „Наставления” Агапита, w: Памятники литературы и общественной мысли эпохи феодализма, ред. Е.К. Ромодановская, Новосибирск 1985, 5-13.

ЗлАТАРски В.И., История на българската държава през средните векове, t. I/2: Първо българско Царство. От славянизацията на държавата до падането на Първото иарство (852-1018), София 1927.

Игнатов В., Българските ичарищи. Владетелките на България от VII до XIV в., София 2008.

Йорданов И., Корпус на печатите на Средновековна България, София 2001.

ЛЕшка М.Й., Образът на българския ичар Борис II във византийските извори, „Studia Balcanica” 25 (2006) 145-152.

Марлановић-Душанић C., Rex Imago Dei: о српској преради Агапитовог огледала, w: Трећа југословенска конферениија византолога, Крушевац, 10-13 мај 2000, Београд - Крушевац 2002, 135-148.

МутАфчиев П., История на българския народ (681-1323), София 1986.

Никитенко Н.Н., Русь и Византия в монументальном комплексе Софии Киевской. Историческая проблематика, Киев 2004.

Никитенко, София Киевская и ее создатели, Каменец-Подольский 2014.

Николов А., Политическа мисъл в ранносредновековна България (средата на IXкрая на Х в.), София 2006.

Николов, Старобългарският превод на „Изложение на поучителни глави към император Юстиниан” от дякон Агапит и развитието на идеята за достойнството на българския владетел в края на IX - началото на X в., „Palaeobulgarica” 24 (2000) fasc. 3, 76-105.

Славова Т., Юридическа литература, w: История на българската средновековна литература, ред. А. Милтенова, София 2008, 194-202.

Сотникова М.П. - СПасский И.Г., Тысячелетие древнейших монет России. Сводный каталог русских монет X-XI вв., Ленинград 1983.

Тодоров Т., Константин Багренородни и династичният брак между владетелските домове на Преслав и Константинопол от 927 г., „Преславска книжовна школа” 7 (2003) 391-398.

ХристодуловА М., Титул и регалии болгарской владетельницы в эпоху средневековья (VII-XIV вв.), „Études Balkaniques” 3 (1978) 141-148.

Чилингиров А., Монетите на киевските князе и монетите на българския цар Петър I, София 2009.

ЩАпов Я.Н., Древнерусские княжеские уставы XI-XV вв., Москва 1976.

ЩАпов, Княжеские уставы и иеековь в Древней Руси XI-XIV вв., Москва 1972.

ЩАпов, Номоканон Иоанна Схоластика и Синтагма 14 титулов у Славян в IX-X вв., w: Beiträge zur byzantinischen Geschichte im 9.-11. Jahrhundert. Akten des Colloquiums Byzanz auf dem Höhepunkt seiner Macht, Liblice, 20.-23. September 1977, hrsg. von V. Vavřinek, Praha 1978, 387-411.

Янин В.Л., Актовые печати Древней Руси X-XV вв., t. 1: Печати X - начала ХІІІ в., Москва 1970. 